\title{
WHY INTERDISCIPLINARY GRADUATE PROGRAM ATTRACT GREAT STUDENTS
}

\author{
Janice Buss \\ Professor and Director, Molecular, Cellular \& Developmental Biology \\ Graduate Program at lowa State University
}

There is broad recognition among the life science disciplines that "interdisciplinary" programs are successful. This success has led to a huge growth in the number of interdisciplinary graduate programs in biosciences in the past two decades. At lowa State University there are now nine such majors available for students interested in life sciences, ranging from Genetics to Water Resources. There is an increasing trend to bundle these programs administratively into larger umbrella "Bioscience" programs that recruit students broadly, provide a common set of foundational didactic courses, then allow the students to select a personalized program of courses and thesis research that may be interdisciplinary or more traditionally based in a department.

The term "inter-disciplinary" is widely used to describe programs that provide graduate training that crosses traditional disciplinary boundaries, such as molecular, cellular and developmental biology. Programs such as these might more appropriately be called "multi-disciplinary" so as not to be construed as offering education in a new, melded area that might emerge between fields. Inter-disciplinary is also used somewhat interchangeably with "interdepartmental," because when crossing disciplinary boundaries, one frequently also crosses departmental boundaries. A program will of course be interdepartmental when there is no standing department that addresses the training area. This is true, for example, for the Graduate Major in Toxicology at lowa State, which has no department of Toxicology. However, some training programs emphasize an area that is dominated by a single department, so the "inter-departmental" term is not universally applicable.

What makes interdisciplinary programs attractive to students that might otherwise join departmental programs, and especially, to high caliber students? There appear to be four primary enticements that interdisciplinary programs can use to their advantage.

First, there is widespread public perception that the leading edge of science crosses old boundaries. This may derive fortuitously from the various science-based programs on public television. High school students, undergraduates, and their teachers have gained an idea of what molecular biology is from shows that reveal with great drama how it can be utilized to solve forensic mysteries or generate transgenic mice that grow twice as big as normal. This attitude is displayed proudly on the web site for The Division of Biology and Biomedical Sciences at Washington University at St. Louis, which advertises: 
"The Division of Biology and Biomedical Sciences at Washington University in St. Louis originated in 1973 as one of the 1st interdisciplinary graduate programs in the nation. This interdisciplinary approach is key to solving emerging biological and biomedical problems in the 'post-genomic' era." The popularity and perceived importance of such collaborative research has fueled an increase in enrollments in these interdisciplinary majors. At lowa State, enrollment in these majors has increased from 250 in 1996 to 340 in 2001, an increase of more than one-third.

There is also growing interest in interdisciplinary research among faculty in academe, because the lines between "traditional" fields such as biochemistry and cell biology are increasingly blurred. Funding sources such as the National Institutes of Health and the National Science Foundation have furthered this blurring by offering support for research that is explicitly "cross-cutting" or "bridging between disciplines." This prominence of collaborative research is often reflected in the reorganization, or at least re-naming, of departments at universities, to publicly demonstrate their changing emphases, and announce that they, too, are at the fore-front.

Second, there are both concrete data and word-of-mouth stories of success showing that students in interdisciplinary programs really are great. The average GRE scores for students in 10 interdisciplinary programs at lowa State are higher than the average for the 10 most closely aligned departmental programs. The caliber of student that is attracted to interdisciplinary programs, by this one limited measure, is demonstrably superior. Faculty members of interdisciplinary programs join primarily because membership gives them access to excellent students.

Third, interdisciplinary programs can include an enticing menu of courses in their curriculum. These courses take advantage of the breadth of expertise of the program's faculty, and also of the courses offered in the various participating departments. Because programs often involve more than a dozen departments, the list of possible courses is far larger than an individual department can advertise.

Fourth, and most important, great students are eager to explore several areas of research. They will often have had research experience through summer internships and be eager for an opportunity to do more. Thus smart applicants look for a wide choice of faculty doing exciting research. Here again, interdisciplinary programs have a clear strength. With a single focus on graduate education, programs can include far more faculty than could be accommodated in a departmental setting. The freedom and choices for a thesis research area that an interdisciplinary program can provide are almost overwhelming.

What are the challenges for making interdisciplinary programs a strong tool for recruiting and training excellent graduate students? There are three 
components that contribute to vitality of a graduate program in any setting, but perhaps most clearly in the interdisciplinary venue: faculty time and commitment, faculty collegiality and common goals, and not surprisingly, money.

Time is perhaps the most crucial challenge for an interdisciplinary program. Programs are motivated by a group of faculty that are not in a single department, and who must therefore also maintain their widely varying departmental responsibilities while contributing time and energy to (often several) interdisciplinary majors. Directors or Chairs of these programs, and certainly members of the necessary program committees, volunteer with the realization that this effort will go largely unrecognized outside of one line on an annual activity report. Enthusiasm and energy are not limitless resources, and wane as the priorities of grant writing, publication and department service supersede. This is a challenge that is correctable, particularly at the departmental administrative level. Departments must recognize and give value for the commitments of their faculty members to the interdisciplinary programs that provide their faculty with high-quality students. Teaching release for program directors is crucial. While grant writing slows, it is especially helpful to give additional support through research assistantships.

A more difficult challenge is the need for program faculty in multiple departments and the departmental members that are not in the program to agree on common goals. This ranges from collegial arrangements and attendance at seminars of the interdisciplinary program to the sometimes tumultuous bargaining that accompanies faculty hiring. This challenge arises precisely because interdisciplinary program curricula cross many departmental boundaries and require faculty that will be hired and assigned through multiple departments. Departments must claim and support these boundaries in their own missions, or there may never be a way to provide the research and teaching expertise that the interdisciplinary program needs. Interdisciplinary programs need faculty members that give voice to the program's needs to develop departmental advocacy in hiring decisions, and security in continued curricular support. Equally, departments and their Chairs need to listen.

The final challenge is, not surprisingly, money. In certain instances, departments may have no graduate recruitment or training program of their own. Other departments may derive substantial numbers of students through these programs. Overall, at lowa State, the enrollment trends for interdisciplinary programs indicate that over one-third of all graduate students will soon be recruited through interdisciplinary programs. Despite this, interdisciplinary programs are often not part of the regular budgeting process that focuses on undergraduate education and is administered through departmental and college channels. This can result in faculty efforts given, benefits produced, but no funds to carry the increasing load. Volunteerism and collegiality can only go so far. Diverting at least a modest sum for the important job of attracting excellent 
graduate students should become part of departmental, college, and university thinking.

In addition, it is common that when students in interdisciplinary programs join a laboratory for their thesis research, they become an administrative responsibility of the "home" department of their major professor. When a department has its own recruitment and training program for its own majors, the question of equality arises. Interdisciplinary students cannot be "Iast on the list" when teaching assistantships or emergency funding are allocated.

Finally, if interdisciplinary programs represent and can advertise their cutting-edge, attractive training, how do the great students choose which to join? Competitive stipends are needed, to be sure. Few programs can take the risk that their reputation is outstanding enough that a student will choose to study with them for $\$ 15,000$ when they might make $\$ 20,000$ (or more) elsewhere. And tuition waivers or payments can add (or subtract) substantially. But within a cohort of institutions providing similar overall funding, good students are immensely influenced by the reputation of the university for making research discoveries. There are no known instances of recruitment based on exciting committees. To students, legislators, journalists, and the general public, the way a university is recognized and remembered is through its research-the insights, the inventions. Research discoveries drive the reputation of universities. In the 1993 NRC survey of Ph.D.-granting programs, faculty publications and citations are one of the few parameters that distinguish one university from another. But research discoveries are not made by faculty directly, and good students know that they will be the first ones that actually get to see that discovery. University administrators need to understand that funding the graduate students and postdoctoral fellows that produce the news-breaking research gives great pay-offs publicly, especially in a time when tuition increases and budget cuts are making headlines. Discoveries in the leading edge of interdisciplinary research require great students with interdisciplinary training, and changes in old ways of investing in graduate education. 